\title{
The Use of Technology by Youth: Implications for Psychiatric Educators
}

\author{
Shashank V. Joshi ${ }^{1} \cdot$ Dorothy Stubbe ${ }^{2} \cdot$ Su-Ting T. Li ${ }^{3} \cdot$ Donald M. Hilty $^{4}$ (D) \\ Received: 15 April 2018 / Accepted: 7 November 2018 / Published online: 16 November 2018 \\ (C) Academic Psychiatry 2018, corrected publication 2019
}

Today's youth are using technology in a variety of ways, from texting and tweeting to chatting, online gaming, and posting through a variety of Internet portals. Of US adults and those aged 18-29, respectively, $88 \%$ and $99 \%$ use the Internet [1]. As of 2017, approximately $95 \%$ of American adults have a cell phone and $77 \%$ a smartphone [1]. Social media — usually defined as web-based and mobile services that allow people to share a connection, monitor progress, and create/manipulate text, audio, photos, and/or video [2,3] —is also exponentially growing [4]. Social media and networking options like Twitter and Facebook are common among the Digital Native ( $Z$; 1998-present), Millennial (Y; 1981-1997), and X (19651980) Generations (Table 1) [5, 6].

On a typical day, American teenagers (13- to 17-year-olds) spend an average of six and a half hours and tweens spend an average of four and a half hours on screen media use. [1, 5, 6]. These behaviors, experiences, and events may be positive or negative, healthy or unhealthy, and normal or problematic. Positive aspects of technology for the youth include being able to speak more freely (finding one's voice/community) online, learning/knowledge gains, communication/engagement with others, and creative exploration. Youth are also open to the use of technology for the assessment and interventions in healthcare, such as web-based technologies which support youth with depressive symptoms [7] and text messaging services as an intervention for adolescent obesity or suicidal thinking [8].

Donald M. Hilty

donh032612@gmail.com

1 Stanford University School of Medicine, Palo Alto, CA, USA

2 Yale University School of Medicine, New Haven, CN, USA

3 University of California Davis School of Medicine, Sacramento, CA, USA

4 Northern California Veterans Administration Health Care System, Sacramento, CA, USA
Despite these potential benefits, concerns about media use - especially excess use - of television and computer games have arisen due to potential changes in mood, promotion of sedentary lifestyles, withdrawal from other activities, and severely impaired sleep patterns [9]. Problematic social media behaviors may range from disinhibition and the posting of ill-advised photos, to more extreme examples like online bullying, sexting, frank exploitation, and other destructive or addictive behaviors [10-15]. Disinhibition of behaviors may be encouraged by the ability to post anonymously [16].

In addition, according to the New York Times, "The nearuniversal access to digital technology, starting at ever younger ages, is transforming modern society in ways that can have negative effects on physical and mental health, neurological development and personal relationships, not to mention safety on our roads and sidewalks" [17]. Concerns about adverse effects of the Internet have led to proactive efforts toward cyberhealth [18], discussion of risks associated with excess online and screen activity [19], and a call for research on how technology "changes" us [20]. Finally, the "opportunity costs" need to be accounted for, that is, time spent on one activity costs an opportunity to spend it on another (perhaps better, healthier) activity.

This paper will examine these issues, with more breadth than depth, in order to:

1) Provide a snapshot of the technologies used by youth and young adults;

2) Help clinicians differentiate between normal use, problematic overuse, or addictive online behavior;

3) Provide a basic approach for clinicians to engage, screen, educate/advise, and assess technology issues to move toward the treatment of specific disorders; and

4) Help communities and institutions tackle challenging issues like cyberbullying, sexting, high-risk behaviors, and problematic Internet use (PIU). 
Table 1 Popular social media sites for youth [source: https://www.stopbullying.gov/cyberbullying/kids-on-social-media-and-gaming/index.html]

Parents and educators may not be aware of the apps that children and teens use regularly or may not be aware of the risks involved. There are many ways that cyberbullying can be hidden in apps and sites, such as texts, videos, and web calls that disappear or do not appear on the device's call or text message logs.

Many sites and apps make it easy for users to access, view or participate in adult or harmful content. Privacy and location settings may make them more vulnerable to stalking, cyberbullying, exposure to adult content, or other dangers.

Some current popular social media venues and apps include:

- Askfm: a social networking site that allows users to ask other people questions, often anonymously.

- Chatroulette: there are over 20 different chat roulette sites that allow users to instantly connect via webcam and video chat. Sites typically pair the users randomly and instantly.

- Facebook and Facebook Live: the most commonly used social media site that is accessible on many different media platforms.

- Instagram: a photo and video-sharing and networking site that connects users through other social networking sites (e.g., Facebook).

- Kik: messaging app that allows users of all ages to contact others anonymously.

- Line: a messaging app that allows users to make free phone calls, leave voice messages, and text. Users can delete texts or chats from recipient's phone using a timer.

- Musical.ly: users can post their own videos and view videos posted by others.

- Reddit: a site that stores social news, rates and evaluates web content, and discussion threads.

- Sarahah: an anonymous messaging app that allows users to send anonymous messages to people they may know.

- Snapchat: a photo messaging app that allows for sharing pictures and short videos that are intended to be erased shortly after delivery.

- Telegram: messaging app that allows users to share photos, videos, and files; make calls, and delete texts or chats from recipient's phone using a timer.

- Tumblr: a social networking site that allows posting of short blogs and media.

- Twitter: a microblogging site that allows users to send, read, and reply to "tweets" or short messages.

- Vine: an app that allows the posting of short 6-s looping videos.

- WeChat: an app that allows the user to chat with friends, and to search for people nearby and around the globe.

- WhatsApp: a private messaging app that allows users to text, send photos, videos, and location information to their contacts.

- YouTube: a video-sharing platform that allows users to post and share videos.

This paper also uses case vignettes to highlight key symptoms, differentiate between normal and abnormal behavior, and help clinicians navigate through clinical challenges.

This approach to problems with technology use is geared to help clinicians across medicine and mental health professions learn and teach others - rather than focus on all of the specific disorders and treatments, which are beyond this paper's scope. PIU is broadly conceptualized as an inability to control one's use of the Internet, which leads to negative consequences in daily life [21]. Universal components that constitute a PIU definition include the inability of a person to control Internet use, preoccupations, urges or behaviors with marked distress, and functional impairments. PIU may represent new psychopathology, behaviors moved to the Internet or a technologyspecific addiction or impulsivity problem.

\section{Use of Technology by Youth and Clinical Ramifications}

\section{Overview}

Texting is the primary means of communication among teens aged 12-17 [22]. Teens text more often than talking on their cell phone, speaking in-person, using instant messaging, sending e-mail, or visiting social network sites [21]. In a recent Pew survey of Internet use in the USA, teens go online daily (92\%), several times a day (56\%) to almost constantly (24\%) [21]. Recent trends from 2018 reveal that the online platform teens use most often was Snapchat (35\%) followed by YouTube (32\%) and Instagram (15\%) (Table 1) [22]. While teens aged 13-17 are the highest users in the pediatric age group, advertisers, and other entities are also targeting tweens aged 8-12 to sell digital media products.

Some have raised concerns that modern connectedness is not evolutionarily natural [23], and that instant gratification [24] fuels problematic use [25, 26] and is replacing physical exercise [27]. Many violent video games include justifications of the portrayed violence, a distorted portrayal of consequences, and dehumanization of opponents [28]. A link to violence is hard to research due to varied populations, uncontrolled studies, and many confounding variables.

\section{Theories for Understanding Problematic Internet Use and Technology Addictions}

Some of the best models for understanding problematic Internet use and technology addiction come from theories on cigarette and alcohol use [29]. For example, the rational addiction model for cigarette use posits that individuals may 
Table 2 Brief case vignettes of youth use of technology on a spectrum from normal to problematic use

Vignette 1.

Presentation. Art is a 17-year-old male who is texting a lot to others about hobbies, recent events, and morbid thoughts. Friends notified his mother who contacted his past therapist. (He has a history of depression and was in therapy at age 11 after losing interest in school/hobbies and conflict with his siblings and parents.) He was texting to friends about stories in the paper in which people died; his friends seemed to be withdrawing and he complained about that. He went on to say that "So what if someone died...it's not that big of a deal." His mother's question was "Is this just teen angst or a sign of a problem?"

Triage/assessment/plan. A prompt phone call was helpful and a plan was put together: (1) the parents would check in with Art to try and understand the situation better; (2) the mother would speak with his teachers(s) and guidance counselor; and (3) a new clinical intake would be set up for Art. Moderate (but not imminent) risk of danger was based upon: (1) history of depression, (2) peer concerns over his text messaging, and (3) morbid thoughts.

Vignette 2 .

Presentation. Tameka is a 13-year-old female whose parents report nearly continuous use of social media since she got her new smartphone (e.g., texting friends during meals, sharing Instagram pictures throughout family vacations, and watching YouTube videos and chatting online while during her homework). Tameka continues to maintain her grades, but her family wants to know "How much is too much?"

Triage/assessment/plan. In this scenario, Tameka's family is concerned about Tameka's Internet use, but it has not affected her grades (yet). The clinician or school counselor might consider screening for problematic Internet use (PIU) using the PRIUSS-3 and if Tameka scores a 3 or higher, she could then be evaluated with the PRIUSS-18 to identify whether she may have a problematic Internet use (PIU) syndrome. Whether or not Tameka has a problematic Internet use, Tameka and her family may benefit from a Family Media Use Plan per the American Academy of Pediatrics to build shared expectations, goals, and rules for media use.

Vignette 3.

Presentation. Joseph is a 15-year-old boy who was referred to a psychiatrist for inattention, hyperactivity, falling grades, and increasingly oppositional behavior. Joe had previously earned good grades and did well on sports teams, so they did not pursue evaluation or treatment. Now, he seems not to care about homework, is failing one subject, and his other grades are low. Notably, he did not sign up for baseball. The family wondered about drug use, but a urine drug test was negative. Last week his father found him playing a video game at 4:00 a.m.

Triage/assessment/plan. In this scenario, Joseph may have symptoms of ADHD or depression and/or PIU. A full psychiatric assessment is indicated, including information from parents, pediatrician, and teachers. A full media-use history (PRIUSS-18 and/or questions from Table 3) may be especially helpful. Non-judgmental rapport-building will be crucial to engaging Joseph to learn what gaming means to him and how it got out of hand (e.g., escape from stresses, to maintain contact with peers, and/or as stimulation-seeking). Psychoeducation will help the family structure and limit his online time (e.g., after he completes homework). Moving the gaming console from his bedroom to a better place to monitor in the house may also help.

Vignette 4.

Presentation. Aaron, an 11-year-old boy is popular and well-connected who begins to post pictures of drug use and YouTube links with mature themes after hours. He no longer spends face-to-face social time with friends but continues to do well academically. Furthermore, his friends have told their parents about his postings, and about an "alternate" Instagram persona Aaron has named "Andre the Giant," where he posts his most provocative pictures and links.

Triage/assessment/plan. It is important for Aaron's parents to share their and others' specific concerns regarding online content. Rules for responsible Internet use should be reviewed in line with family values and beliefs (e.g., respectful and responsible posts). The parents may also remind Aaron that social media and phone use are a "privilege" and not a "right," and set up consequences for problematic posts.

recognize the addictive nature of choices they make, but still make them because the immediate gains from the activity exceed any costs [30]. For any population, there are often inconsistencies between choices, consequences, and misimpressions (e.g., cigarettes do not lead to cancer as much as genetics) [31]. Consumers are much more patient when making decisions about the future than when those same decisions are made today (e.g., to declare their diets will start tomorrow rather than to start the diet today).

Evidence suggests that technology may have addictive properties due to both intrinsic and extrinsic variables [32]. The theory of intrinsic motivation suggests that perceived enjoyment of using the technology system is gratifying in its own right. Extrinsic variables that influence technology usage include perceived ease of use and usefulness, Internet system design, and the emotional states and cognitions that are promoted by the system. The combination of intrinsic and extrinsic motivators may lead to overuse at an elevated level [32]. Individuals who use the Internet and other technologies to the exclusion of other activities may demonstrate negative outcomes similar to other addictions, with negative personal, societal, school, and work-related ramifications [33].

PIU or excess digital media use is defined as the Internet or digital media use that interferes with life functioning, leading to poorer school engagement, poorer academic achievement, and attention/cognition sleep deprivation [34, 35]. Youth at risk for PIU score higher on extroversion and neuroticism scales [36] (e.g., higher levels of anxiety and escapism, and decreased emotional control to help self-regulate use), though these data are correlational. Attention deficit hyperactivity disorder (ADHD) and other psychiatric disorders have also been correlated with PIU, and youth with ADHD and PIU are more at risk for negative effects on sleep, academic achievement, and attention/cognition [37, 38]. More specifically, Internet and video game addiction have gained attention in the literature recently, likely given its problematic effect on adolescent sleep patterns [39]. 
In contrast, studies in the field also highlight that Internet use can increase life satisfaction via online games, help maintain peer connections, and reduce social anxiety [40, 41]. Some Internet activities improve results on tests and increase motivation for learning among young people [42]. Recent investigations have highlighted the potentially major role of e-technologies in supporting youth mental health, including the delivery of mental health services [43]. Because youth-focused strategies are growing rapidly on a global basis, it is critical to study the impact of these technologies.

\section{Differentiating between Normal and Problematic Use}

Vignettes may highlight difficulties, which arise when differentiating between the normal and problematic Internet and social media use (Table 2). When $95 \%$ of US teens go online daily and $45 \%$ go online almost constantly [44], it can be challenging for parents, teachers, and clinicians to differentiate between normal and problematic online activity. In addition, adolescents often engage in media multitasking, with more than $50 \%$ engaging in multiple media activities at a given time, such as being online and watching TV [45]. As is often true with human behavior, there is a spectrum that spans Internet use from normal to problematic [46-52]. Overuse of the Internet in children has been associated with sleep problems, depression and anxiety, poor academic performance and poor social adjustment, and even increased suicide risk [19, 53-56].

Standardized, valid assessment is the key for adolescent and young adult populations and the 18-item Problematic and Risky Internet Use Screening Scale (PRIUSS-18) assesses social impairment, emotional impairment, and risky/ impulsive Internet use [57, 58]. It utilizes a 5-item scale (never $=0$, rarely $=1$, sometimes $=2$, often $=3$, very often $=4$ ) and a score of 25 or higher identifies those at risk for PIU. PIU symptoms are more strongly correlated with recreational Internet use compared to work- or school-related use. Not surprisingly, patients with inattention symptoms correlated most strongly with the risky/impulsive use domain.

A shorter, 3-item PRIUSS was developed to be used as an initial screening tool [59] by employing three screening questions:

- "How often do you experience increased social anxiety due to your Internet use?"

- "How often do you feel withdrawal when away from the Internet?" and

- "How often do you lose motivation to do other things that need to get done because of the Internet?"
A score of 3 or higher on the PRIUSS-3 has a $100 \%$ sensitivity and $69 \%$ specificity for identifying someone with potential PIU, who could then be evaluated using the PRIUSS-18 $[57,58]$.

\section{An Approach for Clinicians and Educators to Engage, Assess, Educate, and Treat Problematic Internet Use (PIU)}

\section{Engagement}

An initial approach might start with acknowledging that the Internet is central to the lives of most teens and young adults, for whom technology literacy is pivotal to academics, work, and play [37]. Among the challenges are gaining an accurate history of online activities and associated health and risk factors. Media use tells a great deal about patients - how they use their time, what they enjoy, how they want others to view them, awareness/ use of privacy settings, proneness to risky behaviors, executive functioning, and awareness of the consequences of behavior. It is also a snapshot about the number and depth of relationships, the types of friends they have, family relationships, cultural selfidentification, and prosocial aspects of Internet use.

The first step is to form a therapeutic alliance with youth and their parents, or with a young adult patient individually. Quality care in psychiatry depends on patient-doctor engagement, the therapeutic relationship with both youth and parent (also known as a dual alliance) and shared decision-making for treatment [60]. As many young people (and adults) may consider the Internet their lifeline to social engagement, consideration of the problematic aspects of Internet use may be met with reluctance. Exploring beliefs, norms, values, cultural and language factors, and the meaning of technology to the individual is integral to understanding and meeting the needs of each patient [61].

\section{Assessment}

Internet use may range from healthy to problematic. Psychiatric educators must become knowledgeable about technology to assist trainees in developing clinical acumen in evaluating patients, including PIU. A complete media history is an essential component of a psychiatric evaluationespecially for tweens and teens. The assessment of youth will be enhanced with multiple informants - parents, significant others, school staff, the primary care provider, and/or others who know her/him well. However, it is also important to normalize media use as something that most people engage in.

The continuum from healthy to problematic use must be explored with youth and parents using a non-judgmental approach. Table 3 provides specific tools to clarify the types and extent of technology used [14, 62-64]. For example, the American Academy of Pediatrics' Media and 
Table 3 Evaluation questions for youth and young adults about media use

\begin{tabular}{|c|c|c|}
\hline Questions & Prompts or specifics & Follow-up questions \\
\hline $\begin{array}{l}\text { Most of us use electronics and devices almost } \\
\text { constantly. Which do you use? }\end{array}$ & $\begin{array}{l}\text { Smartphone } \\
\text { Computer } \\
\text { Tablet } \\
\text { Gaming systems like PlayStation, X-box, Wii } \\
\text { TV } \\
\text { Other }\end{array}$ & $\begin{array}{l}\text { Which do you use the most? } \\
\text { Which is your favorite? }\end{array}$ \\
\hline On which social networking accounts do you & Facebook & Do you use media to deal with stress? \\
\hline have a profile or account? & Twitter & How often? \# hours/day? \\
\hline Which is your favorite? Why? & Instagram & Does media use cause you stress, and if so, how? \\
\hline $\begin{array}{l}\text { Are you "friends" with your parents or } \\
\text { siblings? }\end{array}$ & $\begin{array}{l}\text { YouTube } \\
\text { Tumblr }\end{array}$ & $\begin{array}{l}\text { Content-photos, posts, phone, school, city, birthdate, } \\
\text { etc. }\end{array}$ \\
\hline Do your parents have your passwords? & $\begin{array}{l}\text { Google Plus } \\
\text { Pinterest } \\
\text { E-mail } \\
\text { Snapchat } \\
\text { Video-sharing platforms } \\
\text { Chat rooms } \\
\text { MySpace } \\
\text { Other }\end{array}$ & $\begin{array}{l}\text { Number of friends } \\
\text { Do you personally know all of the friends on your social } \\
\text { media? } \\
\text { How have you set up your privacy settings? } \\
\text { Have you lied about your age to gain access to websites } \\
\text { and online accounts? } \\
\text { Have you interacted with strangers online, and if so, do } \\
\text { you use your real name? } \\
\text { Do you post videos? What kind? }\end{array}$ \\
\hline $\begin{array}{l}\text { How do you usually keep in touch with } \\
\text { friends? }\end{array}$ & $\begin{array}{l}\text { In-person } \\
\text { Phone } \\
\text { Text } \\
\text { e-mail } \\
\text { Other }\end{array}$ & $\begin{array}{l}\text { How often? } \\
\text { How many hours per day? } \\
\text { Do you take photos and videos? } \\
\text { Where do you post? } \\
\text { Have you ever posted or received inappropriate photos? } \\
\text { Have you ever posted something online that caused } \\
\text { problems for you, a friend or family member? }\end{array}$ \\
\hline $\begin{array}{l}\text { What do you like to do on the } \\
\text { computer/tablet? }\end{array}$ & What sites do you go to? & $\begin{array}{l}\text { How often? } \\
\text { Are there any internet sites that you visit that you do not } \\
\text { want your parents to know about? }\end{array}$ \\
\hline What video games do you play? & Which is your favorite? & $\begin{array}{l}\text { How often do you play? } \\
\text { How long? } \\
\text { Alone or with others? } \\
\text { Ratings of the games (T, M, other?) } \\
\text { First person shooter games? }\end{array}$ \\
\hline
\end{tabular}

Does your media use ever cause problems for For screening questions, consider PRIUSS you (or do you use it to avoid stress)? $\quad$ screen (see text of paper for description) or CAGE approach or:

1. Have you ever felt you should cut down on your internet use?

2. Have others annoyed you by criticizing your internet use

3. Have you ever felt bad or guilty because of your internet use?

4. Do you need to look at the Internet first thing in the morning (eye-opener)?

Teens spend an average of 8 h daily using

Compared with the average teen, about how media, including online videos, music, and much screen time do you have daily?

Which types of media do you spend most time with?

How often are you online rather than going to sleep at night?

Have you visited weapons sites? Porn sites? Sites that promote suicide, anorexia, or other things your parents might worry about?

Have you ever had any bad experiences online?

What do you think are positive aspects of the Which specific sites have been helpful to you? Internet and media for you?

Have you gotten health or mental health information online?

Have you used self-help sites?

Have you made friends or gotten closer to a friend online?

Have you used apps that promote wellness? 
Table 3 (continued)

\begin{tabular}{|c|c|c|}
\hline Questions & Prompts or specifics & Follow-up questions \\
\hline & & $\begin{array}{l}\text { Have you ever helped a friend who felt suicidal online or } \\
\text { via text/chat? }\end{array}$ \\
\hline \multirow[t]{8}{*}{ Screen for risky behavior } & $\begin{array}{l}\text { Are you doing things via technology that you } \\
\text { would not usually do? }\end{array}$ & $\begin{array}{l}\text { Have you interacted with strangers online, and if so, do } \\
\text { you use your real name and ID info? }\end{array}$ \\
\hline & $\begin{array}{l}\text { Do you feel bad about anything you have done } \\
\text { via technology? }\end{array}$ & $\begin{array}{l}\text { Have you planned to meet up with someone you met on } \\
\text { the internet? }\end{array}$ \\
\hline & & Have you ever been bullied or harassed online? \\
\hline & & Have you bullied or harassed others online? \\
\hline & & How about pranks? \\
\hline & & $\begin{array}{l}\text { Have you ever posted photos or other posts that you } \\
\text { would not want your parents or future employers to } \\
\text { see? }\end{array}$ \\
\hline & & Do you post videos? What kind? \\
\hline & & Have you ever sexted? \\
\hline
\end{tabular}

Communication Toolkit and Family Media Use Plan [63, 64] emphasizes the family as a whole and takes into account the health, education, and entertainment needs of each individual child as well as the whole family; this may be less awkward and stigmatizing. Evaluation is quite challenging due to a host of factors [62-66], including the patient's behavior and/or problem is based both on the patient's age and developmental level (i.e., a behavior may be normal for one group and not another). Technology may affect the developing brain more than the adult brain $[24,66]$.

Problematic to severely problematic Internet use (PIU) [47] has been proposed as an addition to DSM-5 [37] and "internet gaming disorder" has been proposed as a condition requiring further research. The 11th Revision of the International Classification of Diseases (ICD-11) has recently included "gaming disorder" in its classification scheme. It is defined as a pattern of gaming behavior (i.e., digital gaming or video gaming) characterized by impaired control over gaming, increasing priority given to gaming over other activities to the extent that gaming takes precedence over other interests and daily activities, and continuation or escalation of gaming despite the occurrence of negative consequences.

As Internet use is in dynamic interplay with contextual and activity-related factors, it is important for the clinician to assess the continuum of use, and other factors involved, such as technology availability, peer habits, family rules, and expectations, and aspects of the individual's environment to understand the factors that promote and maintain PIU. If appropriate, asking if the patient would like to share examples of their social media content with clinicians during an office visit can be a method of understanding the interests, values, and habits of patients. Overall, general metrics are needed regarding behaviors, exposure time to/with technology, and "content" exposure. Studies that address the impact of technology on academic achievement - and other behaviors - commonly do so using standardized tests [67].

\section{Education, Advice, and Treatment Principles}

Youth and families will benefit from education about normal Internet use, as well as the hazards of excess screen time, including sleep disruption, diminished academic and social functioning, and exacerbation of pre-existing psychopathology. Motivational interviewing techniques may help coconstruct a plan that meshes with the values and aspirations of the patient. It is helpful to identify the factors that maintain excessive Internet use. A treatment plan is more likely to succeed if it specifies alternative activities that may meet the emotional needs that PIU is currently fulfilling. See Table 3 for psychoeducation about normal use, and treatment tips for teens/young adults and parents to address PIU.

\section{An Approach to Challenging Issues: Cyberbullying, High-Risk Behaviors, and Excess Online Activity}

Problematic social media behaviors may range from disinhibition and the posting of ill-advised photos to more extreme examples like online bullying — known as cyberbullyingand sexting, frank exploitation, and other addictive behaviors [10-14]. For example, sexting is sending, receiving, or forwarding sexually suggestive content, explicit messages, and/or photographs or images $[13,68]$. This may occur between romantic partners, others outside a primary relationship, and/or exchanges between people who are not yet in a relationship. Sexting has become more common with the rise in smartphones with Internet access. It is done by people of all ages, but most media coverage focuses on negative aspects for tweens, teens, and young adults, who use the medium of the text message much more than any other new media to transmit messages of a sexual nature [13-15, 68]. Overall, though, its definition is still a gray area and finding a consensus regarding 
the definition is essential to assess accurately the activity and adapt prevention [69].

Data on bullying and cyberbullying from scientific studies is substantial and of teens who admit to being bullied online are increasingly telling adults (e.g., $60 \%$ in 2014 compared to $40 \%$ in 2013) [12, 13, 69-71]. Cyberbullying can be defined as the willful and repeated harm (i.e., harassing, humiliating, or threatening text or images) inflicted through the Internet, interactive technologies, or mobile phones [12-15, 69-73]. Over $40 \%$ of American teens (13-17 years of age) report experiencing some form of cyberbullying in the past year. Conversely, $11.5 \%$ of teens admitted to having engaged in cyberbullying. Girls are much more likely to be victims of cyberbullying $(>40 \%)$ than boys (29\%). Girls also dominate social media, while boys more frequently play video games $[14,15,70,71]$. In extreme cases, peer victimization experienced through cyberbullying can be directly linked to an increase in suicide risk [12]. Victimization through cyberbullying is more strongly related to suicidal ideation, compared to traditional bullying [12]. This phenomenon is not just limited to teens. A recent meta-analysis found that this phenomenon is true for older as well as younger children, boys as well as girls, and children who were both bullied and who bullied others (previously known as bully/victims). Just owning a cell phone significantly increases cyberbullying risk (both as a victim and perpetrator), among children in grades 3-5 [12].

Playing video games is a popular activity among youth and young adults, with $72 \%$ of teens gaming online [1,34]. Many video games - whether they are console-, web-, or computerbased - allow users to play with friends they know in-person and others they have met only online. A perceived anonymity of players and the use of avatars allow users to create alter-egos or fictional versions of themselves, which is part of the fun of gaming - but it also allows users to harass, bully, and sometimes gang up on other players, sending or posting negative or hurtful messages, and using the game as a tool of harassment $[14,15]$. If someone is not performing well, other children may curse or make negative remarks that turn into bullying, or they might exclude the person from playing altogether. Anonymous users may engage the game as a means to harass strangers or to get their personal information, like usernames and passwords.

There are things adults can do to prevent cyberbullying of children who are gaming:

- Play the game or observe when the gaming happens to understand how it works and what content a child is exposed to in the game.

- Check-in periodically with your child/student about who is online and who is playing the game with them.

- Teach youth about safe online behavior, including not clicking on links from strangers, not sharing personal information, not participating in bullying behavior of other players, and what to do if they observe or experience bullying.
- Establish rules about how much time a child or teen can spend playing video games (for example, 30 min of reading must precede every 30 min of gaming).

\section{Recommendations}

Numerous online resources are available to guide clinicians, parents, teachers, and other trusted adults in a youth's life to respond to and prevent cyberbullying [14]. The following psychoeducational tips are recommended for clinicians, and for parents of teens and younger children regarding Internet safety:

- Stay up-to-date on the latest apps, social media platforms, and digital slang used by children and teens by consulting resources such as Common Sense Media, stopbullying. gov, The Cyberbullying Research Center, and the Pew Research Center Fact sheet on Internet Use [1, 5, 14, 71].

- Monitor their teen's social media sites, apps, and browsing history if there is concern about cyberbullying.

- Review or re-set their child's phone location and privacy settings.

- Follow or friend their teen on social media sites or have another trusted adult do so.

- Know their child's usernames and passwords for email accounts and social media.

- Establish rules about appropriate digital behavior, content, and apps [15, 62-64].

To minimize the risk of cyberbullying or harm from digital behavior, parents can:

- Set clear expectations about digital behavior and online reputation.

- Educate about the harmful effects of cyberbullying, posting hateful speech or comments, sexting, and sharing naked photos of themselves or others (including potential legal issues).

- Be clear about what content can be viewed or shared.

- Identify which apps are appropriate for their child's use and which are not.

- Establish rules about the amount of time that a child can spend online or on their devices.

- Model positive, respectful digital behavior on their own devices and accounts.

\section{Conclusions}

This paper has examined core themes in the Digital Native, Millennial, and $\mathrm{X}$ generations related to the use of 
technologies by tween, teen, and young adults. While the literature focuses primarily on social media and networking, youth engage with media through television, computer/video games, communication by text/e-mail, mobile apps, and video-sharing platforms as well. The brief review of the literature highlighted, that, although many aspects of this new media landscape can be positive, others are problematic. This paper has attempted to give clinicians and others an approach to differentiate the use of technology on a spectrum from normal range to problematic. Systematic reviews of the healthy and unhealthy behaviors in teens, tweens, and other groups are needed, in addition to a more quantitative and qualitative research on the use of technology by youth. Personnel in schools and healthcare institutions have important roles to play in order to help manage the healthy integration of social and other media in this era of digital life.

Acknowledgments American Academy of Child \& Adolescent Psychiatry.

American Academy of Pediatrics.

American Association of Directors of Psychiatric Residency Training.

\section{Compliance with Ethical Standards}

Disclosure On behalf of all authors, the corresponding author states that there is no conflict of interest.

Publisher's Note Springer Nature remains neutral with regard to jurisdictional claims in published maps and institutional affiliations.

\section{References}

1. Pew Research Center. Fact sheet on Internet use. http://www. pewInternet.org/fact-sheet/. Accessed 10/8/18.

2. Boyd DM, Ellison NB. Social network sites: definition, history and scholarship. J Comput-Mediat Commun. 2007;13(1):210-30.

3. Canadian Medical Association. Social media and Canadian physicians - issues and rules of engagement. 2015. https://www.cma.ca/ socialmedia. Accessed 10/8/18.

4. Hilty DM, Chan S, Torous J, et al. New frontiers in healthcare and technology: Internet- and web-based mental options emerge to complement in-person and telepsychiatric care options. J Health Med Informat. 2015;6(4):1-14.

5. Common Sense Media. The common sense census: media use by tweens and teens. https://www.commonsensemedia.org/sites/default/ files/uploads/research/census_researchreport.pdf. Accessed 10/8/18.

6. Pew Research Center. Defining generations: where millennials end and post-Millennials begin. http://www.pewresearch.org/fact-tank/ 2018/04/11/millennials-largest-generation-us-labor-force/ft_18-0402_generationsdefined2017_working-age/. Accessed 10/8/18.

7. Välimäki M, Anttila K, Anttila M, Lahti M. Web-based interventions supporting adolescents and young people with depressive symptoms: systematic review and meta-analysis. J Med Internet Res Mhealth Uhealth. 2017;5(12):e180. https://doi.org/10.2196/ mhealth.8624.

8. Keating SR, McCurry MK. Systematic review of text messaging as an intervention for adolescent obesity. J Am Assoc Nurse Pract. 2015;27:714-20. https://doi.org/10.1002/2327-6924.12264.
9. Carson NJ, Gansner M, Khang J. Assessment of digital media use in the adolescent psychiatric evaluation. Child Adolesc Clin N Am. 2018;27:133-43.

10. Mihajlov M, Vejmelka L. Internet addiction: a review of the first twenty years. Psychiatr Danub. 2017;3:260-72.

11. Pontes HM. Investigating the differential effects of social networking site addiction and Internet gaming disorder on psychological health. J Behav Addict. 2017:13:1-10.

12. Van Geel M, Vedder P, Tanilon J. Relationship between peer victimization, cyberbullying, and suicide in children and adolescents: a meta-analysis. JAMA Pediatr. 2014;168(5):435-42.

13. Englander E. Risky business talking with your patients about cyberbullying and sexting. Child Adolesc Clin N Am. 2018;27: 287-305.

14. Stopbullying.gov. Cyberbullying tactics. https://www.stopbullying. gov/. Accessed 10/8/18.

15. The Resilience Project. We can stop toxic stress. Bullying and cyberbullying. American Academy of Pediatrics. https://www.aap. org/en-us/advocacy-and-policy/aap-health-initiatives/resilience/ Pages/Bullying-and-Cyberbullying.aspx. Accessed 10/8/18.

16. Suler J. The online disinhibition effect. CyberPsychol Behav. 2004;7(3):321-6.

17. Brody JE. Hooked on our smartphones. NY Times; September 1, 2017. https://www.nytimes.com/2017/01/09/well/live/hooked-onour-smartphones.html. Accessed 10/8/18.

18. Saparova D. Motivating, influencing, and persuading patients through personal health records: a scoping review. Persp Health Inf Manag. 2012;9(Summer). www.ncbi.nlm.nih.gov/pmc/articles/ PMC3392953/. Accessed 10/8/18.

19. Carli V, Hoven CW, Wasserman C, Chiesa F, Guffanti G, Sarchiapone M, et al. A newly identified group of adolescents at "invisible" risk for psychopathology and suicidal behavior: findings from SEYLE study. World Psychiatry. 2014;13:78-86.

20. Hilty DM. Technology and the brain: what can we learn from our life experience, patient care, social media and internet use? Psychol Cogn Sci. 2017;3:89-93. https://doi.org/10.17140/PCSOJ-3-128.

21. Lenhart A. Teens, social media and technology overview. Pew Research Center. April 9, 2015. http:/www.pewInternet.org/2015/ 04/09/teens-social-media-technology-2015/. Accessed 10/8/18.

22. Joshi SV. Teamwork: the therapeutic alliance in pediatric pharmacotherapy. Child Adolesc Psychiatr Clin N Am. 2006;15(1):239-62.

23. Piper Jaffrey. 34 th Semi-Annual Taking Stock with Teens ${ }^{\circledR}$ Survey. 2017. http://www.piperjaffray.com/2col.aspx?id=4611. Accessed 10/8/18.

24. Seligman MEP, Tierney J. We aren't built to live in the moment. NY Times; May 17, 2017. https:/www.nytimes.com/2017/05/19/ opinion/sunday/why-the-future-is-always-on-your-mind.html. Accessed 10/8/18.

25. Greenfield S. Screen technologies. 2013. http://www.susangreenfield. com/science/screen-technologies/. Accessed 10/8/18.

26. Bianchi A, Phillips JG. Psychological predictors of problem mobile phone use. Cyberpsychol Behav. 2005;8(1):39-51.

27. Lamblin M, Murawski C, Whittle S, Fornito A. Social connectedness, mental health and the adolescent brain. Neurosci Biobehav Rev. 2017;80:57-68.

28. Morin M. Is your smartphone making you fat and lazy? July 11, 2013. Los Angeles Times. http://articles.latimes.com/2013/jul/11/ science/la-sci-sn-is-your-smartphone-making-you-fat-and-lazy20130710. Accessed 10/8/18.

29. Hartmann T, Krakowiak KD, Tsay-Vogel M. How violent video games communicate violence: a literature review and content analysis of moral disengagement factors. Commun Manag. 2014;7751: 1-23. https://doi.org/10.1080/03637751.2014.922206.

30. Dee T. The complementarity of teen smoking and drinking. J Health Econ. 1999;18:769-93. 
31. Becker GS, Murphy K. A theory of rational addiction. J Polit Econ. 1988;96(4):675-700.

32. Centers for Disease Control and Prevention. Trends in current cigarette smoking among high school students and adults, United States. 2013. http://www.cdc.gov/tobacco/data_statistics/tables/ trends/cig smoking/. Accessed 10/8/18.

33. Turel O, Serenko A, Giles P. Integrating technology addiction and use: an empirical investigation of online auction users. MIS Q. 2011;35:1043-61.

34. Charlton JP, Danforth IDW. Distinguishing addiction and high engagement in the context of online game playing. Comput Human Behav. 2007;23:1531-48.

35. Gentile DA, Bailey K, Bavelier D, Brockmyer JF, Cash H, Coyne $\mathrm{SM}$, et al. Internet gaming disorder in children and adolescents. Pediatrics. 2017;140(Suppl 2):S81-S5.

36. Thorsteinsson EB, Davey L. Adolescents' compulsive Internet use and depression: a longitudinal study. Open J Depression. 2014;3:13-7.

37. American Psychiatric Association. Diagnostic and Statistical Manual. 5th ed. Washington, DC: American Psychiatric Publishing, Incorporated; 2013.

38. Ceranoglu TA. Inattention to problematic media use habits interaction between digital media use and attention-deficit/hyperactivity disorder. Child Adolesc Clin N Am. 2018;27:183-91.

39. Hale L, Kirschen GW, LeBourgeois MK, et al. Youth screen media habits and sleep sleep-friendly screen behavior recommendations for clinicians, educators, and parents. Child Adolesc Clin N Am. 2018;27:229-45.

40. Kowert R, Vogelgesang J, Festl R, Quandt T. Psychosocial causes and consequences of online video game play. Comp Human Behav. 2015;45:51-8.

41. Glover J, Fritsch SL. Kids, anxiety and social media: a review. Child Adolesc Clin N Am. 2018;27:171-82.

42. Guan SSA, Subrahmanyam K. Youth internet use: risks and opportunities. Curr Opin Psychiatry. 2009;22:351-6.

43. Boydell KM, Hodgins M, Pignatiello A, et al. Using technology to deliver mental health services to children and youth: a scoping review. J Can Acad Child Adolesc Psychiatry. 2014;23(2):87-99.

44. Pew Research Center. Teens, social media, and technology $2018 \mathrm{http}: / /$ assets.pewresearch.org/wp-content/uploads/sites/14/2018/05/ 31102617/PI 2018.05.31 TeensTech FINAL.pdf. Accessed 10/8/18.

45. Moreno MA, Jelenchick L, Cox E, et al. Problematic Internet use among US youth: a systematic review. Arch Pediatr Adolesc Med. 2011;165(9):797-805.

46. Moreno MA, Jelenchick L, Koff R, Eikoff J, Diermyer C, Christakis DA. Internet use and multitasking among older adolescents: an experience sampling approach. Comput Human Behav. 2012;28(4):1097-102.

47. Anderson EL, Steen E, Stavropoulos V. Internet use and problematic Internet use: a systematic review of longitudinal research trends in adolescence and emergent adulthood. Int J Adolesc Youth. 2017;22(4):430-54.

48. Rafla M, Carson NJ, DeJong SM. Adolescents and the Internet: what mental health clinicians need to know. Curr Psychiatry Rep. 2014;16:472-83.

49. Maher CA, Lewis LK, Ferrar K, Marshall S, de Bourdeaudhuij I, Vandelanotte C. Are health behavior change interventions that use online social networks effective? A systematic review. J Med Internet Res. 2014;16(2):e40.

50. Newman S. Teens and the internet: how much is too much? 2010. https://www.psychologytoday.com/blog/stepmonster/201004/ teens-and-the-Internet-how-much-is-too-much. Accessed 10/8/18.

51. Council on Communications and Media. Media use in school-aged children and adolescents. Pediatrics. 2016;138(5).

52. Dalope K, Woods LJ. Digital media use in families: theories and strategies for intervention. Child Adolesc Clin N Am. 2018;27: $145-58$.
53. LeBourgeois MK, et al. Digital media and sleep in childhood and adolescence. Pediatrics. 2017;140(Suppl 2):S92-S6.

54. Hoge E, Bickham D, Cantor J. Digital media, anxiety and depression in children. Pediatrics. 2017;140(Suppl 2):S76-80.

55. Romer D, Moreno M. Digital media and risks for adolescent substance abuse and problematic gambling. Pediatrics. 2017;140(Suppl 2):S102-S6.

56. Robinson TN, Banda JA, Hale L, Lu AS, Fleming-Milici F, Calvert SL, et al. Screen media exposure and obesity in children and adolescents. Pediatrics. 2017;140(Suppl 2):S97-101.

57. Jelenchick LA, Eickhoff J, Christakis DA, et al. The problematic and risky Internet use screening scale (PRIUSS) for adolescents and young adults: scale development and refinement. Comput Human Behav. 2014;35. https://doi.org/10.1016/j.chb.2014.01.035.

58. Jelenchick LA, Eickhoff J, Zhang C, Kraninger K, Christakis DA, Moreno MA. Screening for adolescent problematic internet use: validation of the problematic and risky internet use screening scale (PRIUSS). Acad Pediatr. 2015;15(6):658-65.

59. Moreno MA, Arseniev-Koehler A, Selkie E. Development and testing of a 3-item screening tool for problematic Internet use. J Pediatr. 2016;176:167-72.

60. Hilty DM, Srinivasan M, Xiong G, et al. Lessons from psychiatry and psychiatric education for medical learners and teachers. Int Rev Psychiatry. 2013;25:329-37.

61. Hilty DM, Snowdy CS, Shoemaker EZ, et al. Social media, e-health and clinical practice: tips for clinicians, guidelines and exploring pathological internet use. Med Res Arch. 2016;3(7). http://www. journals.ke-i.org/index.php/mra/article/view/292. Accessed 10/8/18.

62. My Digital TAT2. This Silicon Valley nonprofit organization focuses on how to build healthy habits, critical thinking, and thoughtful online behavior across the lifespan. http://www.mydigitaltat2.org. Accessed 10/8/18.

63. American Academy of Pediatrics. Family media use plan. https:// www.healthychildren.org/English/media/Pages/default.aspx. Accessed 10/8/18.

64. American Academy of Pediatrics Media and Communication Toolkit. https://www.aap.org/en-us/advocacy-and-policy/aap-healthinitiatives/Pages/Media-and-Children.aspx. Accessed 10/8/18.

65. Mayhew A, Weigle P. Media engagement and identity formation among minority youth. Child Adolesc Clin N Am. 2018;27:269-85.

66. Hilty DM. Advancing science, clinical care and education: shall we update Engel's biopsychosocial model to a bio-psycho-sociocultural model? Psychol Cogn Sci. 2016;1(1). https://doi.org/10. 17140/PCSOJ-1-e001. Accessed 10/8/18.

67. Bavelier D, Green CS, Dye MWG. Children, wired - for better and for worse. Neuron. 2010;67(5):692-701.

68. Drouin M, Vogel KN, Surbey A, et al. Let's talk about sexting, baby: computer-mediated sexual behaviors among young adults. Comput Human Behav Elsevier. 2012;29(5):25-30.

69. Internet Safety 101. http://internetsafety 101.org. Accessed 10/8/18.

70. Cox 2014 Internet Safety Survey, 2014. The Futures Company. https://www.cox.com/content/dam/cox/aboutus/documents/tweeninternet-safety-survey.pdf. Accessed 10/8/18.

71. Cyberbullying Research Center. https://cyberbullying.org. Accessed 10/8/18.

72. Gold J. Screen-smart parenting. How to find balance and benefit in your child's use of social media, apps, and digital devices. New York: Guilford Press; 2015.

73. Selkie EM, Fales JA, Moreno MA. Cyberbullying prevalence among United States middle and high school aged adolescents: a systematic review and quality assessment. J Adolesc Health. 2016;58(2):125-33. 